Article

\title{
Making Structural Change with Relational Power: A Gender Analysis of Faith-Based Community Organizing
}

\author{
Sarah B. Garlington *, Margaret R. Durham Bossaller, Jennifer A. Shadik and Kerri A. Shaw \\ Department of Social Work, Ohio University, Athens, OH 45701, USA; E-Mails: garlingt@ohio.edu (S.B.G.), \\ margaretsmail@gmail.com (M.R.D.B.), shadik@ohio.edu (J.A.S.), shawk@ohio.edu (K.A.S.) \\ * Corresponding author
}

Submitted: 23 January 2019 | Accepted: 23 April 2019 | Published: 24 June 2019

\begin{abstract}
This article presents research on faith-based community organizing in the US to examine how congregation members engage in structural change efforts related to marginalized populations. Examining the case of one organizing model, justice ministry, congregations focus on power defined through relationships, cultivated in informal spaces, and communicated through personal narrative (traditionally private, feminine spheres), and change is enacted by creating tension in public (traditionally masculine) spaces with decision-makers. A growing body of literature presents nuanced gender analyses of policy advocacy, social movements, and community change efforts both in terms of strategic models of action and revisiting our understanding of historical movements. We ask questions about how the expectations and work are constrained or facilitated by cultural expectations of gender roles and power dynamics. Examining the organizing model of justice ministry through a gender lens helps to understand how an emphasis on relational power (traditionally gendered as feminine) facilitates and strengthens the use of a range of tools, including publicly challenging authority (more frequently gendered as masculine). While the private/public, feminine/masculine dichotomy has severe limitations and risks oversimplification, the utility remains in helping name and challenge real power differentials based on gender.
\end{abstract}

\section{Keywords}

faith-based community organizing; gender; justice ministry; power analysis; relational power; religion

\section{Issue}

This article is part of the issue "Exhausted Women-Exhausted Welfare: Understanding Religion, Gender and Welfare in Social Inclusion", edited by Martha Middlemiss Lé Mon (Uppsala University, Sweden).

(C) 2019 by the authors; licensee Cogitatio (Lisbon, Portugal). This article is licensed under a Creative Commons Attribution 4.0 International License (CC BY).

\section{Introduction}

When we investigate the role of religion in welfare policies and provision, we often focus on how dominant religious traditions shape cultural discourse around welfare (and hence welfare policy) or how congregations help meet welfare needs at the community level. This article presents research on faith-based community organizing $(\mathrm{FBCO})$ in the US to examine how congregation members engage in structural change efforts related to marginalized populations and those most often part of welfare systems. In the case of one national organization's model of justice ministry, congregations focus on power defined through relationships, cultivated in informal spaces, and communicated through personal narrative (traditionally private, feminine spheres), and change is enacted by creating tension in public (traditionally masculine) spaces with community decision-makers.

\section{Justice Ministry and Community Organizing}

FBCO is a widespread movement that draws primarily from congregational groups to engage in local advocacy and solve community problems. National or regional organizing networks typically provide structure and training to congregants of member organizations (Flaherty \& 
Wood, 2004; Fulton \& Wood, 2012; Jones, 2015). FBCO efforts tend to focus on issues of local concern to middleand lower-income people in urban areas (Flaherty \& Wood, 2004; Swarts, 2008; Wood \& Warren, 2002). Specific topics addressed by FBCO groups vary widely but often have a common theme of striving for justice and equality for the disadvantaged (Galluzzo, 2009; Stout, 2011; Warren, 2001; Wood \& Warren, 2002).

The model of national FBCO networks providing training and member groups joining to work for change at the local level grew out of Saul Alinsky's community organizing work in industrial Chicago in the 1940s (Galluzzo, 2009; Hart, 2001; Jones, 2015; Stout, 2011; Swarts, 2008; Warren, 2001). During this period, Alinsky founded Industrial Areas Foundation (IAF), which remains a major network for FBCO (Hart, 2001; Jones, 2015; Stout, 2011; Swarts, 2008; Warren, 2001). Over time this model, which was initially both church- and neighborhoodbased, became increasingly infused with religious meaning (Hart, 2001; Stout, 2011; Warren, 2001). Important influences on FBCO include the non-violent protests of the Civil Rights Movement and the corresponding religious teachings of Dr. Martin Luther King Jr, whose thought had been influenced by Mahatma Gahandi (Baker, 2010; Jacobsen, 2017; Salvatierra \& Heltzel, 2014; SlessarevJamir, 2011). Catholic social teachings and the Catholic Worker movement, the Protestant social gospel, liberation theology, and the Jewish commitment to Tikkun olam all contributed to the development, growth, and shaping of FBCO (Baker, 2010; Hart, 2001; Jacobsen, 2017; Salvatierra \& Heltzel, 2014; Slessarev-Jamir, 2011). Additionally, influences from Latin America, such as the Sanctuary Movement, teachings on liberation theology, and the work of Cesar Chaves and Paulo Freire, have been especially strong for FBCO networks with hubs in the southwestern US (Bretherton, 2015; Hart, 2001; Salvatierra \& Heltzel, 2014; Slessarev-Jamir, 2011).

There are a number of core elements that tend to be common across the various FBCO networks and that aid in bolstering the effectiveness of $F B C O$ in addressing or overcoming the problems Alinsky identified as impacting organizing efforts. Among these core elements are the guiding principles of power and relationships.

The justice ministry model is one FBCO strategy used by one of the major national organizing networks. The particular emphasis on an explicitly religious worldview and the conceptualization of community problems as based on a scripturally-grounded belief in resource abundance rather than resource scarcity sets the justice ministry model apart from other faith-based organizing. While the overall goal of justice ministry is to advocate for and enact community level structural changes to benefit marginalized populations, the stated measures of success are focused on increased community relationships, leadership development of congregation members (both women and men), and other social inclusionoriented factors. This case looks at the day-to-day work and strategies of four community organizations in the jus- tice ministry national network, and how the integration of private/feminine and public/masculine spheres contributes to social inclusion, both in structural changes to benefit marginalized populations and in cultivating relational power and community capacity.

\section{Gender Analysis}

A growing body of literature presents nuanced gender analyses of policy advocacy, social movements, and community change efforts (Duin et al., 2015; Orloff, 2009; Peterson, 2012; Swank \& Fahs, 2013), both in terms of strategic models of action and of revisiting our understanding of historical movements (such as the Civil Rights Movement in the US). A gender analysis examines the work of individuals, groups, and institutions through a lens of cultural values and "social relationships" (Orloff, 2009 , p. 318) related, but not isolated, to sex (as a biological category) and gender (as a social category). We ask questions about how the expectations and work are constrained or facilitated by cultural expectations of gender roles and power dynamics. This article looks at the organizing model of justice ministry through a gender lens to understand how an emphasis on relational power (traditionally gendered as feminine) facilitates and strengthens the use of a range of tools, including publicly challenging authority (more frequently gendered as masculine).

Factors such as race/ethnicity, sexual orientation, social class, or physical ability also add layers of power differentials, though a full intersectional analysis is beyond the scope of this article. Certainly, one of the key components of any gender-related analysis is understanding power dynamics and how these are constructed through social relationships on multiple levels. Intersectionality analytical frameworks emphasize that power dynamics and experiences of social identity factors cannot be reduced to additive layers (e.g., gender + race/ethnicity) but that social relationships "converge to produce a social location that is different than just the sum of its parts" (Hankivsky, 2014, p. 255). Collins (2000) writes that the various social identity factors and social locations shift in meaning based on context, and individuals' experiences of privilege and oppression are connected to that contextual significance. In discussing the justice ministry model, a thorough intersectional analysis would at least need to examine the interplay of gender, race/ethnicity, socioeconomic class (including education), and (dis)ability. Focusing on gender as an "anchor point" (Christensen \& Jensen, 2012, p. 112) for this discussion allows us to connect the tools of this organizing model with categories of public and private that are often gendered, knowing that the experiences of the communities and organizers cannot be distilled singly to gender.

While the private/public, feminine/masculine dichotomy has severe limitations and risks oversimplification, the utility remains in helping name and challenge real power differentials based on gender. Research litera- 
tures shows that historically divisions in labor (workforce and home), income, political participation, educational attainment, and beyond are shaped by gender and related cultural role expectations, even as our cultural values around gender are shifting (Barreto, Ryan, \& Schmitt, 2009; Morgan, 2006; Sen, 2014). In trying to understand how we value types of community change work and how power is developed, gender plays an ongoing role (and can contribute to discussions of other factors as well). Martin (2002) writes that the traditional gendered division of public and private spheres influences how individuals participate in community organizing activities. Especially when discussing welfare policy and programoriented change, gender is significant because women are disproportionately the population most directly impacted (Orloff, 2009).

In the field of community organizing, the traditional model of Saul Alinsky emphasizes the power of community members as expressed through organizers bringing local concerns to larger public spaces and challenging public authorities (Stall \& Stoecker, 1998). In the decades since Alinsky's work (Alinsky, 1971), communities have utilized and adapted the strategies in a variety of ways. Scholars have used gender analyses to examine other change strategies, including the success of public space-oriented work due to more private sphereoriented strategies: "leaders are often mobilized by the masses they will eventually come to lead" (Robnett, 1996, p. 1664). One example of this is the ongoing discourse about the Civil Rights Movement in the US in which the success attributed to the charismatic leading men is challenged by the historical community building activities of women activists (Van Delinder, 2009).

\subsection{Women and the Private Sphere}

As discussed above, the association between women (and the traditionally feminine) and the private sphere stems from the historical and cultural social relationships and divisions of labor. The private sphere references caretaking activities in the home, personal relationships, and family-oriented support. Women's caregiving role shapes access to opportunity and definitions of appropriate or valued skillsets, including an emphasis on "interdependence" and relationships (Orloff, 2009, p. 324). These roles in formal job markets often have fewer economic benefits (wages and other compensation).

From a community organizing perspective, "womencentered" (Stall \& Stoecker, 1998), "family-centered" (Cossyleon, 2018), and "feminine style" (Peeples \& DeLuca, 2006) types of organizing include a focus on developing relationships, personal narratives as authoritative information, and other empowerment-oriented strategies: "personal tone, disclosure of personal experiences, reliance on anecdotes and analogies as primary forms of evidence, use of inductive structure, and encouragement of audience identification and participation" (Peeples \& DeLuca, 2006, p. 65). Relational power requires engagement in change processes based on relationships with organizers and witnessing organizers' relationships with others (Gutierrez \& Lewis, 2012) and an orientation to process over task (Mizrahi \& Greenawalt, 2017). Focusing on relational power does not preclude the use of tension or conflict (as discussed below). Some research shows that working in communities predominantly made up of women requires setting aside public conflict as strategy and cultivating "community ties, economic independence, and education" (Cossyleon, 2018 , p. 4). Other research, however, emphasizes the role relational power plays in empowering women and other marginalized community members to speak publicly and challenge authority (Gutierrez \& Lewis, 2012; Krauss, 1998).

Gender socialization also shapes the experiences of individual community members and views of the effectiveness of their efforts. Itzhaky and York (2000) found that greater access to power to enact community change came through acting as "community representatives" for men and through engaging with organizations for women (Itzhaky \& York, 2000, p. 232). Addressing community needs requires a variety of roles and activities, and seeing change come from organizing efforts is key to sustaining community member involvement. This view of effective roles connects with the previous discussions of women being more process-oriented and the next section discussing traditional public roles for men.

\subsection{Men and the Public Sphere}

A necessary step in addressing any community concern is defining the problem and identifying where the decisionmaking power lies to address the problem. Getting the attention of decision-makers often then requires finding or creating opportunities for public exchanges that a legislator or other official cannot avoid: "An Alinsky style of organizing that represents a male-dominated, public and confrontational sphere in which activists seek to gain power for a neighborhood" (Martin, 2002, p. 334). Officials wield power by restricting access to the processes and spaces in which decisions are made, and challenging these restrictions is a significant part of advocating for social change.

However, challenging authority and creating public tension push against many cultural norms, especially for the socialization of women to be peacekeepers and avoid conflict (Gutierrez \& Lewis, 2012). The experience of cultural norms extends beyond gender to factors such as race/ethnicity, sexual orientation, dis/ability, and social class. Though an in-depth examination of these is beyond the scope of this article, the example of African American women's role in the Montgomery, Alabama boycott during the Civil Rights Movement in the US demonstrates the significance of both gender and race in community organizing: "they [African American women] were willing to work behind the scenes, rather than spearheading the boycott themselves, because they thought it was im- 
perative that African American men's leadership be supported" (Gutierrez \& Lewis, 2012, p. 224).

\section{Justice Ministry and Gendered Power}

\subsection{Methodology}

This discussion of FBCO is based on a larger project examining the role of congregations in meeting community social welfare needs. One national US FBCO network and five cities of the 21 where affiliated groups are located were chosen as the pilot sample. The five cities were chosen based on geographic proximity and age of the affiliated group. The affiliated groups ranged from $20+$ years to 1 year in length of existence, and one group is no longer active. Each city's affiliated group employs at least one formal community organizer (except the inactive group) and has at least 10 congregational members. For the study, an initial series of qualitative interviews was conducted with congregational leaders and members (7), community members (4), and organizers (4). For each city and affiliated FBCO group, interviews were conducted with at least one of the organizers and at least one community member not directly involved in the affiliated group. Congregational leaders and members of the affiliated FBCO group were then contacted based on information from the organizers and other community contacts.

The researchers also observed community and organizational meetings of various types (at least two per city) and attended several regional trainings regarding the implementation of the justice ministry model. As described below, the organizing model operates on an annual cycle, and the meetings chosen for observation represented all parts of the cycle. While observations of meetings through the annual cycle were not conducted for all five cities, researchers did attend and observe all four major public events in the cities with active affiliated organizations.

The analysis of the stakeholder interview and meeting observation data was structured by themes drawn from the literature (used to construct the interview guide) and then the emerging themes from the data content. Using inductive/emic analytic principles, the data were organized using the interview guide as a descriptive analytic framework of sensitizing concepts, into both theorybased and respondent-based themes (Patton, 2002). This content analysis allowed for distillation of these data themes into concepts that could then inform the development of theory regarding the FBCO model.

The implementation of this organizing model involves an annual cycle of one-on-one meetings between congregation members and leaders, congregations members and community members, and organizers and congregation members; house meetings led by congregation members to discuss community concerns; community meetings to vote on which concern to develop into a campaign; small group meetings with stakeholders to research the concern and solutions; and finally a large public event in which decision-makers are called upon to commit to making specific, concrete changes towards the solution identified by the community group. Paid organizers for the justice ministry organization in each city facilitate connections between congregational leaders (formal and informal) and train community members (congregational members) to build individual relationships and hold the meetings that constitute the model.

Organizers do not lead house, community, or public meetings but instead provide the support and structure for members to develop leadership skills and craft personal narratives for the purpose of social change. Members are also trained and expected to raise the majority of the funds for the organization's budget. The large public events held annually are structured to present personal narratives related to the campaign's focus (chosen community concern) along with statistical data and evidencebased intervention recommendations. Decision-makers relevant to the concern and intervention are invited to sit on stage in front of a large public audience while the narratives and data are shared, and then they are asked to respond with a yes or no to the specific interventions requested by the community group.

The event's success is founded on the relationships organizational members have cultivated over time, shown by how many individuals show up in the audience and the personal narratives shared, and on the structure of putting the spotlight on decision-makers. Authority is challenged by inviting decision-makers to a communityorganized public space and not allowing them to guide the conversation. In some cases, community members leading the public event must challenge a decision-maker in this public space if the person is unwilling to answer a request with a simple yes or no. From the beginning, the justice ministry model includes discussions of why challenging authority and creating tension are necessary change strategies, and organizers talk through the feelings of discomfort members may feel.

\subsection{Justice Ministry and Gender}

A gender analysis of the justice ministry community organizing model has a wealth of potential avenues for building knowledge about community change and social dynamics. As discussed above, a gender framework can include examining representation, traditional roles and expectations, cultural values, and intersections with other social identity factors such as race/ethnicity, socio-economic class, (dis)ability, geographic location, etc. While the sample size of this pilot study is too small to analyze representation in a meaningful way, one interesting observation was the predominance of participating community members who were women in contrast to the fairly equal distribution of women and men in the other roles (organizers and congregational leaders). Also, the majority of community members and congregational leaders interviewed and observed at related meetings 
were, on average, middle age or older, in contrast to a wider range of age for the organizers. In the small interview sample, the distribution of race/ethnicity was fairly even; however, we did not collect data about any demographics of each organization as a whole. Interviewees did discuss the importance of cross-race organizing as a component of the justice ministry model, in the context of relationship-building more generally. A fully intersectional gender analysis of the justice ministry model will build in these rich discussions and will be possible as we expand beyond the pilot study. From the pilot study, we can apply a gender framework to the emphasis on relational power as the key community change strategy of the justice ministry model.

\subsection{Justice Ministry and Power}

Examining gender in power and change strategies can be based on representation-identifying the gender identities of individuals engaged in different types of strategies (public- or private-oriented, relationship- or conflictoriented) and how these reflect social dynamics and power differentials. This article looks instead at how the FBCO strategies bring private, relational, traditionally feminine activities into public change efforts, beyond the gender representation in community members, organizers, congregational leaders, etc. In using private sphere, traditionally feminine activities such as relationship building to engage people for community change in public spaces, where traditionally masculine values of individual, confrontational leadership are more present, FBCO and the justice ministry model specifically shift power dynamics to enact social justice changes in the community. Because the justice ministry model also values the more traditionally masculine strategies of creating tension and public accountability, the gendered private/public dichotomy itself is challenged. The significance of a gender analysis in this understanding of public/private-oriented strategies is the contributions to understanding power.

The concept of power in FBCO is typically defined as the ability to act or the ability to act effectively (Baker, 2010; Hart, 2001; Jacobsen, 2017; Swarts, 2008). While it is acknowledged that corruption and coercion can occur in the context of power, they are recognized as outcomes that are distinct from power itself (Hart, 2001; Swarts, 2008). FBCO trainers emphasize that power is inherently based on relationships and is available to anyone willing to make the effort to build it, rather than operating in a zero-sum model (Bretherton, 2015; Hart, 2001; Jacobsen, 2017; Swarts, 2008).

More than simply based on relationships, the FBCO perspective argues that power is nurtured in relationships and grows out of relationships (Hart, 2001; Jacobsen, 2017; Swarts, 2008). Building power, particularly among the oppressed or disenfranchised, is considered the central goal of FBCO work (Hart, 2001). As one congregational leader (a Black man from a Baptist church) describes, relationships constitute the community in a way that enables it to make change:

The core of it is relationship building. That's the core. It's all about relationships...it's really about meeting people where they are, developing relationships, getting to know them. And as a result of that, we can make a difference, because we're really becoming a community that's standing for something. (Congregational leader \#1, 2018)

Flaherty and Wood's (2004) study also emphasizes the extent to which power is not easily extricated from the context of relationships in FBCO. In a discussion of the specific skills FBCO participants acquire in this work, they focus on the process of relationship building as necessary for "mutual trust" and in "learning how to act in the public arena": "One leader said that her understanding of a leader changed from one who has the ideas and carries them out, to one who has connections and ties to people, some concerns, and skills in bringing people together" (Flaherty \& Wood, 2004, p. 25). This is consistent with the understanding of power as being rooted in relationships-a concept that is strongly supported by the FBCO maxim that leaders are simply people who have followers (Hart, 2001; Swarts, 2011).

The importance of relationships in FBCO is based primarily on two premises: 1 ) that, as discussed above, power resides in relationships, and 2) people are fundamentally interconnected (Baker, 2010; Bretherton, 2015; Hart, 2001; Jacobsen, 2017; Swarts, 2008). Noting that our very humanity hinges on relationships, Baker (2010, p. 150) writes that "to be human is to be in relationship". Jacobsen (2017) extends the essential nature of relationship to FBCO work in categorizing this work as essentially relational and arguing that organizing is about relationships before it is about issues and it strives to "move toward empowerment, community, and justice" (Jacobsen, 2017 , p. 87), all of which have little meaning outside of relationships. One congregational member (a White woman from a Catholic church) interviewed in the study frames the change work as the relationships: "The basic premise is that if you are intentional about building strong relationships within your congregation, all the rest of it, all the social justice stuff takes care of itself more or less" (Congregational member \#2, 2018).

In the context of organizing work, relationships are understood to involve mutual respect, trust, reciprocity, and often, though not always, emotional connection (Baker, 2010; Bretherton, 2015; Hart, 2001; Jacobsen, 2017; Stout, 2011). Moreover, relationships are understood to involve authenticity, the practice of listening openly, and personal encounter (Baker, 2010; Bretherton, 2015; Stout, 2011). A congregational member interviewee (a White woman from a Jewish synagogue) emphasizes the need for engaging each other on a variety of levels, not just about the major concerns: "our goal is to bring everybody together to meet [about] 
the small things, but also to meet [about] these big things that happen in our community and I think we built a lot of, um, trust in our community" (Congregational member \#3, 2018).

Importantly, though FBCO identifies power as rooted in relationships, relationships are not viewed solely as a means of accessing power. Instead, developing relationships is believed to be a powerful end in its own right (Hart, 2001). Moreover, the building and growth of relationships is viewed as a means by which the already eroded and increasingly deteriorating civil society of the US might be restored, at least in part by the increase in social capital FBCO brings (Bretherton, 2015; Hart, 2001; Warren, 2001; Wood \& Fulton, 2015; Wood \& Warren, 2002).

The importance of relationship in the context of potentially adversarial relationships is further emphasized by the FBCO teaching that the acts of challenging others or attempting to hold them accountable should only occur in the context of a relationship (Hart, 2001). This teaching is based, at least in part, on the premise that true and lasting change is only likely to occur in the context of a relationship (Baker, 2010), though FBCO models also emphasize the difference between private/personal relationships and public/professional relationships. Public relationships should not be held hostage by personal relationships, i.e., public authorities must expect to be challenged. One of the interviewees (a Black man from a Baptist church) talks about the use of "tension" as strategy in public relationships that can be uncomfortable in a personal relationship context:

In our trainings, they [justice ministry organizers] tell us we need to make sure that there's a difference between the personal and business relationship, okay. There's a significant difference, and you can't-one of the criticisms that they [public authorities] always throw at us is that, "Well, you know, you're good church people. You're supposed to be kind and compassionate, understanding, not confrontational", and like that. But we believe in tension, and we don't mind tension, you know. Dr. King says that. You have to have that creative tension. So sometimes we work at creating tension. (Congregational leader \#1, 2018)

The justice ministry model also utilizes the tension strategies and structures public events to include and hold decision-makers accountable. An interviewee (White man from a Lutheran church) describes the organizing goal being centered on the process more than the result and how that engages community members in the decision-making and accountability: "Campaigns are about 20 percent about actually winning....and about 80 percent...generating a crisis in an actual, like, concrete, political struggle that people can get involved in and we can build power around" (Congregational member \#4, 2018).

The time and energy put into the relational power are seen as necessary to the foundation of the pub- lic events, partly to insure a big community audience and partly to building the community members' comfort level with creating tension. One organizer (a White woman) describes the difficulty members struggled with in publicly holding a political leader accountable: "There were lots of people in the crowd who said 'oh my goodness, I couldn't believe that we kept pushing him because he's been in the system so long, he obviously cares'" (Organizer \#1, 2018). Organizers and community members alike discussed the ongoing conversations required to communicate the strategies and to practice the actions that pushed members out of their comfort zones. As one member (a White woman from a Catholic church) said:

You realize these issues are things that we work on because people in our congregations experience it in their personal lives as a problem. So when we are putting these strategies in place to push officials, you know, to implement solutions to them, it's like the choice is often after a certain point either pack up your bags and go home and don't get it done or, you know, use power, be confrontational when necessary. (Congregational member \#2, 2018)

The justice ministry FBCO model relies on the interdependence of power cultivated in private and public spaces.

While the justice ministry model pulls together a range of strategies from traditional community organizing, the radical primacy of relationships in the day-to-day work of the organizations gives insight into how valuing the historically marginalized spheres and roles of women can move change strategies forward. The data presented in this case do not provide a concrete evaluation of the successes of the justice ministry model, but the longevity of some of the community organizations in this initial study provide support for its success. Evaluative research questions would add significant weight and nuance to future discussions.

\section{Power Analysis and Social Change}

With a gender lens, the significance of bringing together multiple strategies contributes to the critical analysis of power required to enact long-lasting social change. Orloff (2009) writes that even our Western understanding of citizenship, the foundation of the welfare state, is gendered: "Citizenship has long been understood in exclusively masculine terms...as rational, autonomous, unburdened by care, impervious to invasions of bodily integrity" (Orloff, 2009, p. 333). Developing change strategies that cultivate multiple types of power helps transform the definitions of citizenship, participation, and the social problems welfare policies try to address.

Gaventa (2009) identifies space, level, and form/visibility as dimensions for analyzing power dynamics as well as for framing different points of access. Participation in democratic processes requires access to decision-making spaces and "the right to define and 
to shape that space" (Gaventa, 2009, p. 26), including defining the public sphere (Werbner, 1999). We must acknowledge that global, national, and local forces shape each other and the access to power at each level. Finally, power takes visible, hidden, and invisible forms based on who has access to participatory spaces and in what places (Gaventa, 2009).

Within this power analysis framework, relationships become the source of knowledge and movement towards opening up closed spaces and making hidden and invisible forms of power transparent. Confrontation and challenging authority are useful strategies for pushing the boundaries of spaces where power is located, but unearthing the invisible boundaries of participation requires relationships.

\section{Conclusion}

We know from the extensive literature on welfare policy and cross-national comparisons that gendered power dynamics are interwoven into the development of policy and the definitions of the social problems welfare policy tries to address. Research also shows that the work of social welfare provision falls disproportionately on women, meaning poorly designed and restricted welfare policy impacts women both as benefit recipients and as providers (Holman, 2014; Monnat, 2010; Morgan, 2006). This article presents qualitative data and supporting literature emphasizing that social change-oriented community organizing (faith-based or otherwise) must cultivate relational power, in addition to other strategies. While relational power traditionally has been seen as part of women's work in the private sphere, organizing models such as justice ministry demonstrate the value and relevance of relationships in making community change and in strengthening other types of community power (such as publicly challenging authority). Stout (2011, p. 66) writes: "To feel anger is to have the importance of the relationship and its demands drawn to our attention". Valuing relationships in community building helps validate social change work traditionally done by women and supports the need for all community members to engage and invest in relationships. These strategies also facilitate new ways of thinking about power dynamics represented in social welfare policy and provision and how we meet the needs of the most marginalized members of our communities.

\section{Acknowledgments}

The authors are grateful for the thoughtful comments and suggestions from the reviewers and to Dr. Martha Middlemiss Lé Mon for the invitation to submit to this thematic issue.

\section{Conflict of Interests}

The authors declare no conflict of interests.

\section{References}

Alinsky, S. D. (1971). Rules for radicals. New York, NY: Vintage.

Baker, K. C. (2010). When faith storms the public square: Mixing religion and politics through community organizing to enhance our democracy. Hampshire: Circle Books.

Barreto, M., Ryan, M. K., \& Schmitt, M. T. (Eds.). (2009). Psychology of women book series. In M. T. Schmitt \& M. K. Ryan (Eds.), The glass ceiling in the 21st century: Understanding barriers to gender equality (pp. 3-18). Washington, DC: American Psychological Association.

Bretherton, L. (2015). Resurrecting democracy: Faith, citizenship, and the politics of a common life. New York, NY: Cambridge University Press.

Christensen, A., \& Jensen, S. Q. (2012). Doing intersectional analysis: Methodological implications for qualitative research. NORA-Nordic Journal of Feminist \& Gender Research, 20(2), 109-125.

Collins, P. H. (2000). Black feminist thought: Knowledge, consciousness, and the politics of empowerment (2nd ed.). New York, NY: Routledge.

Cossyleon, J. (2018). "Coming out of my shell": Motherleaders contesting fear, vulnerability, and despair through family-focused community organizing. Socius: Sociological Research for a Dynamic World, 4, 1-13. https://doi.org/10.1177/2378023117734729

Duin, D. K., Golbeck, A. L., Keippel, A. E., Ciemins, E., Hanson, H., Neary, T., \& Fink, H. (2015). Using genderbased analyses to understand physical inactivity among women in Yellowstone County, Montana. Evaluation and Program Planning, 51, 45-52. http:// dx.doi.org/10.1016/j.evalprogplan.2014.12.006

Flaherty, M. A. F., \& Wood, R. L. (2004). Faith and public life: Faith-based community organizing \& the development of congregations. Syosset, NY: Interfaith Funders Retrieved from https://digitalrepository.unm. edu/soc_fsp/17

Fulton, B., \& Wood, R. L. (2012). Interfaith community organizing emerging theological and organizational challenges. International Journal of Public Theology, 6, 398-420.

Galluzzo, G. (2009). Faith-based organizing-A justice ministry: A strategy for Ministry. International Journal of Public Theology, 3(1), 108-114. https://doi. org/10.1163/156973209X387343

Gaventa, J. (2009). Finding the spaces for change: A power analysis. IDS Bulletin, 37(6), 23-33. https:// doi.org/10.1111/j.1759-5436.2006.tb00320.x

Gutierrez, L. M., \& Lewis, E. A. (2012). Education, participation, and capacity building in community organizing with women of color. In M. Minkler (Ed.), Community organizing \& community building for health \& welfare (3rd ed., pp. 215-228). New Brunswick, NJ: Rutgers University Press.

Hankivsky, O. (2014). Rethinking care ethics: On the 
promise and potential of an intersectional analysis. The American Political Science Review, 108, 252-264.

Hart, S. (2001). Cultural dilemmas of progressive politics: Styles of engagement among grassroots activists. Chicago, IL: The University of Chicago Press.

Holman, M. R. (2014). Sex and the city: Female leaders and spending on social welfare programs in US municipalities. Journal of Urban Affairs, 36(4), 701-715.

Itzhaky, H., \& York, A. (2000). Empowerment and community participation: Does gender make a difference? Social Work Research, 24(4), 225-235. https://doi. org/10.1093/swr/24.4.225

Jacobsen, D. A. (2017). Doing justice (2nd ed.). Minneapolis, MN: Fortress Press.

Jones, D. L. (2015). The organizational context of faithbased community organizing: Effects on member civic engagement. Journal of Human Behavior in the Social Environment, 25(5), 361-374. https://doi.org/ 10.1080/10911359.2014.930363

Krauss, C. (1998). Challenging power: Toxic waste protests and the politicization of white, working-class women. In N. Naples (Ed.), Community activism and feminist politics: Organizing across race, class, and gender (pp. 129-150). New York, NY: Routledge.

Martin, D. G. (2002). Constructing the 'neighborhood sphere': Gender and community organizing. Gender, Place \& Culture, 9(4), 333-350. https://doi.org/10. 1080/0966369022000024678

Mizrahi, T., \& Greenawalt, J. (2017). Gender differences and intersectionality in community organizing. Journal of Community Practice, 25(3), 432-463. https:// doi.org/10.1080/10705422.2017.1356784

Monnat, S. M. (2010). Toward a critical understanding of gendered color-blind racism within the US welfare institution. Journal of Black Studies, 40(4), 637-652. https://doi.org/10.1177/0021934708317739

Morgan, K. J. (2006). Working mothers and the welfare state: Religion and the politics of work-family policies in Western Europe and the United States. Stanford, CA: Stanford University Press.

Orloff, A. (2009). Gendering the comparative analysis of welfare states: An unfinished agenda. Sociological Theory, 27(3), 317-344. https://doi.org/10.1111/ j.1467-9558.2009.01350

Patton, M. Q. (2002). Qualitative research and evaluation methods. New York, NY: Sage Publications.

Peeples, J., \& DeLuca, K. (2006). The truth of the matter: Motherhood, community and environmental justice. Women's Studies in Communications, 29(1), 59-87. https://doi.org/10.1080/07491409.2006.10757628

Peterson, J. (2012). The great crisis and the significance of gender in the US economy. Journal of Economic Issues, 46, 277-290. https://doi.org/0.2753/JEI00213624460203
Robnett, B. (1996). African-American women in the Civil Rights Movement, 1954-1965: Gender, leadership, and micromobilization. American Journal of Sociology, 101(6), 1661-1693.

Salvatierra, A., \& Heltzel, P. (2014). Faith-rooted organizing: Mobilizing the church in service to the world. Downers Grove, IL: InterVarsity Press.

Sen, G. (2014). Sexual and reproductive health and rights in the post-2015 development agenda. Global Public Health, 9(6), 599-606. https://doi.org/10.1080/ 17441692.2014 .917197

Slessarev-Jamir, H. (2011). Prophetic activism: Progressive religious justice movements in contemporary America. New York, NY: New York University Press.

Stall, S., \& Stoecker, R. (1998). Community organizing or organizing the community? Gender and the crafts of empowerment. Gender \& Society, 12(6), 729-756.

Stout, J. (2011). Blessed are the organized: Grassroots democracy in America. Princeton, NJ: Princeton University Press.

Swank, E., \& Fahs, B. (2013). An intersectional analysis of gender and race for sexual minorities who engage in gay and lesbian rights activism. Sex Roles, 68, 660-674. https://doi.org/10.1007/s11199-0120168-9

Swarts, H. (2008). Organizing urban America: Secular and faith-based progressive movements. Minneapolis, MN: University of Minnesota Press.

Swarts, H. (2011). Drawing new symbolic boundaries over old social boundaries: Forging social movement unity in congregation-based organizing. Sociological Perspectives, 54(3), 453-477. https://doi.org/10. 1525/sop.2011.54.3.453

Van Delinder, J. (2009). Gender and the civil rights movement. Sociology Compass, 3(6), 986-999. https://doi. org/10.1111/j.1751-9020.2009.00239.x

Warren, M. R. (2001). Dry bones rattling: Community building to revitalize American democracy. Princeton, NJ: Princeton University Press.

Werbner, P. (1999). Political motherhood and the feminisation of citizenship: Women's activisms and the transformation of the public sphere. In N. Yuval-Davis \& P. Werbner (Eds.), Women, citizenship \& difference (pp. 221-245). London: Zed Books.

Wood, R. L., \& Fulton, B. R. (2015). A shared future: Faithbased organizing for racial equity and ethical democracy. Chicago, IL: University of Chicago Press. https:// doi.org/10.7208/chicago/9780226306162.001.0001

Wood, R. L., \& Warren, M. R. (2002). A different face of faith-based politics: Social capital \& community organizing in the public arena. International Journal of Sociology \& Social Policy, 22(9/10), 6-54. https:// doi.org/10.1108/01443330210790148 


\section{About the Authors}

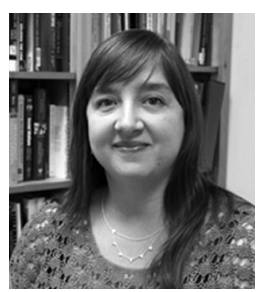

Sarah B. Garlington (Dr.) is an Assistant Professor in the Department of Social Work at Ohio University. She completed her PhD (Social Work \& Sociology) at Boston University, MPhil (Ecumenics) at Trinity College, Dublin, and MSSW at the University of Tennessee. Her research and teaching focus on how communities define and address social problems, with a focus on the role of congregations and other faith-based organizations.

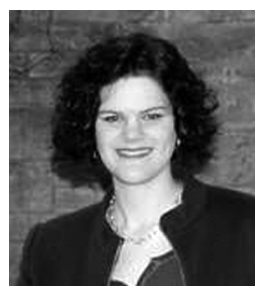

Margaret R. Durham Bossaller completed her MSW at Ohio University and MA (Psychology) at the University of Missouri. She currently works as a hospice social worker in Cleveland, Ohio, and in clinical practice, with a specialty in treating individuals experiencing eating disorders. She is licensed in Ohio (LSW).

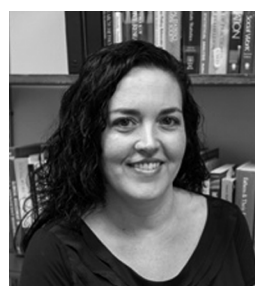

Jennifer A. Shadik (Dr.) is an Assistant Professor at Ohio University in Athens, Ohio. She graduated from Virginia Commonwealth University with a PhD in social work. She spent many years as a practicing social worker, primarily working with families and groups. Her research interests include: fathering, enhancing interventions for parents who have abused or neglected a child, parenting education, and sibling violence. She is licensed in Ohio (LISW) and Virginia (LCSW).

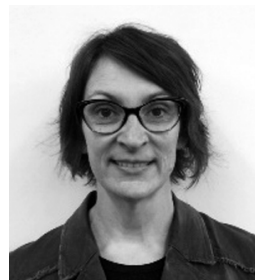

Kerri A. Shaw is the Social Work Field Director and an Associate Lecturer at Ohio University. She was recognized as the 2014 Athens Foundation Woman of the Year for her work in the community and identified as a Community Builder by the Aspen Institute Weave Project in 2018. She earned a bachelor's and master's degree in social work from Ohio University, is a Returned Peace Corps Volunteer, and is a fierce advocate and activist for women and children in Appalachia. 